\title{
Immunocytochemical Evidence that Secretion of Pectin Occurs During Gel (Gum) and Tylosis Formation in Trees
}

\author{
D. Rioux, M. Nicole, M. Simard, and G. B. Ouellette
}

First, third, and fourth authors: Natural Resources Canada, Canadian Forest Service, Laurentian Forestry Centre, P.O. Box 3800, Sainte-Foy, Quebec G1V 4C7, Canada; and second author: ORSTOM, Institut Français de Recherche Scientifique pour le Développement en Coopération, Laboratoire de Phytopathologie, B.P. 5045, 34032 Montpellier, France. Accepted for publication 19 February 1998.

\begin{abstract}
Rioux, D., Nicole, M., Simard, M., and Ouellette, G. B. 1998. Immunocytochemical evidence that secretion of pectin occurs during gel (gum) and tylosis formation in trees. Phytopathology 88:494-505.

During gel (gum) formation in angiosperm trees, fibrillar material accumulated in protective layers of xylem parenchyma cells before being secreted across half-bordered pit membranes into vessel elements. Immunogold labeling demonstrated that this fibrillar material was mainly composed of partially esterified pectic polysaccharides. The primary wall of expanding tyloses, an extension of the parenchyma protective layer, secreted similar pectic substances to completely block vessel elements.

In most studies, these occluding structures were reported to be formed in response to causative factors such as aging processes, injuries, or infections. Current observations support the view that partial to complete embolism, which almost always accompanies these factors, might be the main cause triggering the formation of vessel occlusions. Whereas pectin seems to be the basic component of gels (gums) and of the external layer of tyloses, other substances, such as phenols, were also detected either as a part of these plugs or as accumulations beside them in vessels. Finally, it is proposed that the term 'gel' instead of 'gum' be used in future studies to describe the occluding material secreted by ray and paratracheal parenchyma cells.
\end{abstract}

During xylem dysfunction, one of the most common histological changes observed in angiosperm trees is the occlusion of vessels by gels (gums) and tyloses. This dysfunction may be caused by normal aging processes, injuries, or infections. At the species level, there is only one type of structure, gels (gums) or tyloses, that develops to occlude the vessel lumina of these trees (10). These occlusions have also been commonly reported in herbaceous species: e.g., tyloses in tomato $(7,24)$, cassava $(23)$, and cotton (25); and gels (gums) in chrysanthemum (49) and carnation (2, 18). Following infections or injuries, gels and tyloses have been shown to act as a defense mechanism involved in limiting either xylem (vessel) colonization or the extent of embolism.

Despite some reports suggesting that gels (gums) arise from the swelling of pit membranes and vessel perforation plates (52), a consensus seems to have been reached that these plugs are formed by material secreted from adjacent xylem parenchyma cells through membranes of half-bordered pit pairs, as clearly demonstrated in many microscopic studies $(7,12,18,22,39,43-45)$. At the transmission electron microscope (TEM) level, some studies revealed that the material had a fibrillar structure $(12,43-45)$ and that it could accumulate within and move across the protective layer of parenchyma cells before being secreted into adjacent xylem elements (43-45).

The chemical nature of gels (gums) is still not completely elucidated, apparently because of the use of different histochemical stains that may react with many constituents of the plant tissues. For instance, using such histochemical tests, Gagnon (17) concluded that gums in Ulmus americana were composed of lignin and pectin following positive staining reactions obtained over material in vessels that would have been released from the host walls as a result of the action of fungal enzymes produced by the Dutch elm disease pathogen. Ludwig (24) studied the tomato wilt caused

Corresponding author: D. Rioux; E-mail address: drioux@cfl.forestry.ca

Publication no. P-1998-0406-03R

(C) 1998 The American Phytopathological Society by Fusarium oxysporum f. sp. lycopersici and noted the presence of a few tyloses in vessel elements that were, however, intensely occluded by gums. After observing the apparent physical properties of such gums, he concluded that they contained pectin. It has since been reported that such gels in infected tomato might arise following the action of pectolytic enzymes of pathogenic origin (54). In a review paper on the structural responses that occur in plants following infection, Aist (1) pointed out that these occlusions were poorly characterized, although lignin or polyphenols were occasionally reported as possible components. Whatever their composition, gels (gums) eventually may become impregnated by fungitoxic substances that often appear to be phenolics, as suggested by toluidine blue staining $(18,23,39)$. Likewise, tyloses have been proposed as occluding structures allowing the accumulation of phytoalexin compounds (25).

To our knowledge, Bonsen and Kucera (10) were the first to propose that tyloses in some tree species may also secrete small amounts of gummy material during their expansion in vessel elements. This secretion would show similarities with the production of analogous substances directly from parenchyma cells during gel formation. It has been shown, by using monoclonal antibodies specific for pectic polysaccharides, that the external wall layer of tyloses was composed of pectic compounds (38). Similar observations were subsequently reported in vessels of Xanthomonas campestris-infected cassava xylem (23). It was also postulated that pectin might be produced similarly in the process of gel (gum) formation (38). The current paper substantiates this postulate and suggests hypotheses to explain why this type of secretion occurs during gel and tylosis formation, the two mechanisms by which angiosperm trees occlude their vessel elements. Finally, as some confusion still exists in the literature over the use of the terms 'gel' and 'gum' (the term 'gel' will hereafter be used as a synonym of 'gum'), in all likelihood to describe the same occluding material, the discussion also bears on the reasons why the term 'gel' should be adopted for describing the plugging material secreted by xylem parenchyma cells. 


\section{MATERIALS AND METHODS}

Tree material. The production of gels was studied in the following species: Prunus pensylvanica L.f., Ulmus americana L., Sorbus americana Marsh., and Hevea brasiliensis (Willd. ex A. Juss.) Müll. Arg. Populus balsamifera L. and U. americana were the tree species selected for the examination of tyloses.

Except for $H$. brasiliensis, the inoculation procedure was performed as previously described (38-40). Briefly, from 1984 to 1986, field-grown trees were inoculated in almost equal numbers with either an aggressive isolate of Ophiostoma ulmi (Buisman) Nannf. (695) or a nonaggressive one (Q412). Controls were injected with sterile distilled water. For the following details, the first number in parentheses represents a minimum of trees inoculated and the second number represents a minimum of controls for each species: Prunus pensylvanica (100,100), Populus balsamifera (100,80), S. americana $(75,50)$, and $U$. americana $(50,25)$. For the last species, 28 greenhouse-grown trees were also inoculated and 14 were injected with water. The inoculation surface of branches (1 to 3 years old) was sterilized with $70 \%$ ethanol, and a $200-\mu$ d droplet of a suspension of $O$. ulmi propagules containing mostly conidia at a concentration of $1.0 \times 10^{7}$ cells per $\mathrm{ml}$ was inoculated into the branch using a razor blade. In 1988 (40), as the nonaggressivity of isolate Q412 was questioned (A. Brasier, personal communication), 10 trees of Prunus pensylvanica and Populus balsamifera were also inoculated in the field with either the isolate 695 or another nonaggressive isolate (M273), or injected with sterile distilled water. Samples were generally collected 2 to $3 \mathrm{~mm}$ to $1 \mathrm{~cm}$ above the inoculation point at various periods of time following inoculation, but mostly around 6 to 15 days $(38,39)$. Numerous nonwounded branches were also studied. For $U$. americana, about 50 branches from naturally infected trees showing various intensities of external symptoms (that likely represented infections caused by aggressive isolates of $O$. ulmi) were also collected in 1988. Reasons for our selection of nonhost trees are discussed elsewhere $(39,40)$. All samples were examined in light and transmission electron microscopy, and at least eight samples from inoculated branches and four from control branches of each species were treated by immunochemistry for pectin and examined at the TEM level (discussed below).

The method of inoculating the roots of 1-month-old $H$. brasiliensis seedlings with Rigidoporus lignosus (Klotzsch) Imaseki has been previously described $(29,30,31)$. Five preinfected rubber wood fragments were applied against the taproot of each seedling at a soil depth of $20 \mathrm{~cm}$. Only four samples collected 5 months postinoculation were studied in the current study.

Tissue processing for microscopy. For all species but $\mathrm{H}$. brasiliensis, samples were fixed with $2 \%$ glutaraldehyde in $0.1 \mathrm{M}$ sodium cacodylate buffer (SCB) ( $\mathrm{pH} 7.2)$ for 2 to $3 \mathrm{~h}$ and rinsed three times with SCB before postfixation with $1 \% \mathrm{OsO}_{4}$ in $\mathrm{SCB}$ for $1 \mathrm{~h}$. They were gradually dehydrated with increasing ethanol concentrations and embedded in Epon 812. Samples of H. brasiliensis were prepared according to Nicole and Benhamou (30). Briefly, they were fixed with $3 \%$ glutaraldehyde in $0.1 \mathrm{M} \mathrm{SCB}$ $\left(\mathrm{pH} 7.2\right.$ ) for $2 \mathrm{~h}$ and postfixed with $1 \% \mathrm{OsO}_{4}$ for $1 \mathrm{~h}$. They were also dehydrated with ethanol, but embedded in Araldite.

For observations with a Polyvar light microscope (Reichert, Vienna), sections (about $1 \mu \mathrm{m}$ ) were stained with toluidine blue $\mathrm{O}$ and safranin $\mathrm{O}$ as previously described (39). To detect suberin, the lignin autofluorescence was masked with phloroglucinol- $\mathrm{HCl}$ and sections were examined under violet light excitation as in previous studies $(37,38,40)$. For electron microscopy, sections (about $90 \mathrm{~nm}$ ) were contrasted with uranyl acetate and lead citrate and examined with a Philips 300 TEM (Philips Electron Optics, Eindhoven, the Netherlands) operating at $80 \mathrm{kV}$. At the TEM level, the presence of suberin can also be revealed by the location of the suberized wall layers, as they are usually one of the last laid down by the cell, and by their typical lamellar structure.
Colloidal-gold labeling. Pectic polysaccharides were detected using rat monoclonal antibodies raised against polygalacturonic acid. These antibodies, JIM5 and JIM7 (provided by K. Roberts, John Innes Institute, United Kingdom), recognize unesterified and esterified pectin epitopes, respectively (20). Sections collected on nickel grids were floated on a drop of buffer A (0.01 M phosphate-buffered saline [PBS], $1 \%$ bovine serum albumin [BSA], and $0.05 \%$ Tween 20; $\mathrm{pH} 7.1$ ) for $10 \mathrm{~min}$ and then incubated with JIM5 or JIM7 for $2 \mathrm{~h}$ at $37^{\circ} \mathrm{C}$. Sections were rinsed with buffer A and then floated on a drop of buffer B $(0.02 \mathrm{M}$ Tris-HCl, $1 \%$ BSA, and $0.05 \%$ Tween 20; $\mathrm{pH} 7.2$ ) for $5 \mathrm{~min}$ before incubation with a goat anti-rat antibody (immunoglobulin $\mathrm{G}$ ) complexed to colloidal gold $(15 \mathrm{~nm})$ (BioCell Research Laboratories, Cardiff, United Kingdom) and diluted in buffer B. Sections were thereafter rinsed with buffer B and with filtered distilled water and contrasted as described above. Control tests included (i) omission of JIM antibodies, and (ii) incubation with JIM antibodies previously adsorbed with polygalacturonic acid or citrus pectin.

An exoglucanase with affinity for $\beta(1 \rightarrow 4)$-D-glucans was prepared as described by Benhamou et al. (6) to obtain an enzymegold complex having gold particles measuring $15 \mathrm{~nm}$ in diameter. The enzyme (provided by C. Breuil, Forintek Canada) was used to detect cellulosic material in the different cellular structures studied. For labeling, sections on nickel grids were floated on a drop of PBS (pH 6.5) containing $0.02 \%$ polyethylene glycol (PEG) (molecular weight 20,000) for $5 \mathrm{~min}$ and then incubated with the enzyme-gold complex diluted in PBS-PEG for $30 \mathrm{~min}$. Before contrasting for examination with the TEM, sections were rinsed with PBS and thereafter with filtered distilled water. Control tests were carried out using the enzyme-gold complex previously adsorbed with $\beta(1 \rightarrow 4)$-D-glucans.

\section{RESULTS}

General observations. All isolates of $O$. ulmi induced similar histological changes in a particular nonhost species. In $U$. americana, comparable histological changes were observed independently of the isolate used, except that aggressive isolate 695 induced a greater number of vessel occlusions in a given branch. To detect pectin, the labeling was generally more intense with JIM5 than with JIM7 monoclonal antibodies, a fact that is reflected by the greater number of micrographs presented herein with the former antibody. Because of the absence of significant labeling in the cytoplasm using these antibodies, it was impossible to identify a type of organelle that could be involved in pectin synthesis. During the examination of gel production, an electron-opaque layer was at times observed covering half-bordered pit membranes (described in Discussion). Gels and tyloses were sporadically observed in fibers (data not shown), and their general appearance was similar to that described below for vessel elements. All the control tests for colloidal-gold labeling gave negative results, with only scattered gold particles bound to the section.

The occlusion of vessels by gels and tyloses began around 4 to 6 days postinoculation at 2 to $3 \mathrm{~mm}$ from the inoculation wound. Such occlusions were observed more frequently in samples collected in more advanced infection than in those taken early after inoculation. However, it was also clear that, for a given time after inoculation, some parenchyma cells could only begin to secrete pectic material, while other cells in the same section could apparently have completed such a process, since their protective layer was devoid of significant labeling for pectin (discussed below) and they were observed next to completely occluded vessel elements. In water-injected controls, these occlusions were at times observed, but were very sparse, and they were generally absent from nonwounded branches.

Gels (gums). Prunus pensylvanica. The labeling of the protective layer of xylem parenchyma cells obtained with sections from samples collected from healthy or water-injected branches was gen- 
erally weak or absent following incubations with JIM5 or JIM7 (Fig. 1A), whereas it was usually intense with the exoglucanasegold probe (Fig. 1B). In Figure 1, it can also be noted that gold particles were rare within the lumen of vessel elements.

Following inoculation with $O$. ulmi, the formation of gels was common in vessel elements of the invaded xylem. Staining with toluidine blue and safranin gave a red color to most of these occlusions, but some were tinged red and blue and at times predominantly blue (Fig. 2A). Whereas the exoglucanase labeling in inoculated samples appeared similar to that obtained with the healthy or water-injected material, the immunolabeling for pectin was much more intense in the infected material. In cells that apparently had begun to react to infection, the protective layer of parenchyma cells was always heavily labeled, while pectin appeared to occur rather discretely in vessel elements (Fig. 3A). In other cases, similarly labeled material had accumulated in pit chambers, and it was at times covered by other types of material showing an amorphous structure (Fig. 3B). This phenomenon was often accompanied by the retraction of the plasma membrane, and this was always observed along the adjacent vessel element and was more pronounced in the vicinity of half-bordered pit membranes (Fig. 3C). The labeled material had a fibrillar structure that could be observed within the vessel element and in the protective layer (Fig. 3D). This material was occasionally observed in periplasmic areas between the retracted plasmalemma and the protective layer (Fig. 4A). Numerous unlabeled vesicles were seen from time to time close to the labeled fibrillar material within the protective layer or in the space left by the retraction of the plasma membrane (Fig. 4B).

In advanced stages of infection, most vessel elements in the invaded area were partially to completely occluded by the fibrillar material accompanied by more compact masses. These masses were either labeled and had a fibrillo-granular appearance (Fig. 4C) or, more commonly, they presented an amorphous structure and did not react with the JIM antibodies (Fig. 4D and E). The unlabeled masses were composed of bands of material that formed an alveolar network when these were not collapsed. An electronopaque demarcation could be occasionally observed at the point of juncture of such bands (Fig. 4E). When parenchyma cells were apparently no longer metabolically active, their cytoplasm appeared degenerated or at least very abnormal; the labeling for pectin over the protective layer was less pronounced, but it was abundant over the occluding material in vessel elements (Fig. 4D).

U. americana. In nonwounded branches, pectic polysaccharides were detected in the protective layer of some ray and paratracheal parenchyma cells, but not in most of the xylem living cells present in the same sections.

In water-injected branches, the protective layer of parenchyma cells was more intensely labeled than in untreated samples, and the number of gold particles found in vessel lumina was usually greater than in background labeling (data not shown), but much less so than in inoculated branches. In inoculated material, the accumulation of pectin was intense in protective layers, in the pit membranes of half-bordered pits, and in their covering caps (Fig. 5A). At a higher magnification, gold particles were seen to be attached to a few scattered fibrils (Fig. 5B). In samples collected at longer times after inoculation or in xylem areas where the secretion process seemed more advanced, this fibrillar material was found to partially to completely block the vessel elements, although some unlabeled compact masses appeared to be intermixed with these fibrils (Fig. 5C). Figure 5C also shows a parenchyma cell that might still be involved in secreting pectin material.

S. americana. The inoculated material showed a response quite similar to that observed in Prunus pensylvanica. Immunolabeled fibrils accumulated at the beginning within the protective layer, but were rarely present in pit chambers (Fig. 6A). In more advanced infections, the accumulation of this labeled material was intense within vessel elements (Fig. 6B), and most of the occluded material had a fibrillar structure that was easily discernible when it was loosely aggregated (Fig. 6C).

$\boldsymbol{H}$. brasiliensis. The occluding material was shown to be heterogeneous in vessel elements following the routine histochemical staining procedure (Fig. 2B). As with the other species observed at the TEM level, the labeling with JIM5 was only positive over the parts of the material with a fibrillar arrangement (Fig. 6D). Figure $2 \mathrm{~B}$ also reveals the presence of a tylosis, although such structures were not seen with the few samples observed using electron microscopy.

Tyloses. As observed in Populus balsamifera, the expanding tyloses could produce large amounts of fibrillar material usually intensely labeled with JIM monoclonal antibodies (Fig. 7A and B). As only a primary wall was observed to limit this type of tyloses at this stage, they were considered as still being in expansion. Intense labeling over material present in the cytoplasm and the primary wall of tyloses has already been described (38), suggesting that it was produced by these occluding structures and secreted through their walls. When a suberized layer was formed internally to the primary wall in tyloses that had completed their expansion, the primary wall was almost entirely devoid of gold particles and the secretion process had apparently stopped completely. This pectinaceous matter apparently was eventually pushed by the primary wall of the expanding tyloses into areas difficult to block, such as the region where two tyloses met the vessel secondary wall (Fig. 7B).

Similar observations were noted in $U$. americana (Fig. 7C), except that it was frequently difficult to distinguish whether the fibrillar material came from the tyloses, the parenchyma cells, or both (Fig. 7D). The presence of a suberized wall layer and the weak labeling over the protective layer of some parenchyma cells (Fig. 7D) seemed to indicate that the secretion had ceased in these cells. As described for gels in vessel elements, the material composing the external wall layer of tyloses sporadically had a globular appearance and was not immunolabeled.

A schematic representation summarizing the results is given in Figure 8.

\section{DISCUSSION}

In all the gels observed, the immunolabeling indicated that pectic substances were the basic components of this plugging material in the vessel lumina of the trees examined. As the monoclonal antibodies JIM5 and JIM7, specific for pectin epitopes, have been successfully used in many investigations $(9,20,23,51,53,57)$, the results obtained here with these cytochemical tools appeared to be reliable and likely more so than those presented in histochemical investigations on the same subject. Our findings also are in agreement with other TEM observations that described the fibrillar nature of the material secreted during gel formation (12), and particularly with those reported for Betula, Tilia, Quercus, and Fagus (43-45). It was also shown in these tree species that the material was secreted via the protective layer of xylem parenchyma cells during gel formation, even though vessel occlusion in the last two species is usually achieved by tylosis formation. Many other types of ultrastructural studies reported that pectin in plants is mainly composed of microfibrils, and this was always more evident when the material presented a loosened arrangement $(35,37,51,53)$.

Bonsen and Kucera (10) were the first to propose that tyloses may secrete gummy materials in a manner similar to that of gel production by parenchyma cells. A summary of our results (Fig. 8) shows that the pectic material in vessel lumina may either originate from the tylosis primary wall, which is actually the continuation of the protective layer as reported by others $(10,26,32)$, or directly from the protective layer during gel formation. Thus, whether encased in a parenchyma cell or free in a vessel lumen as part of the tylosis wall, this layer may fulfill the same function of allowing the transport of pectic fibrillar material before secretion into adjacent conducting xylem elements. This assumption is indi- 


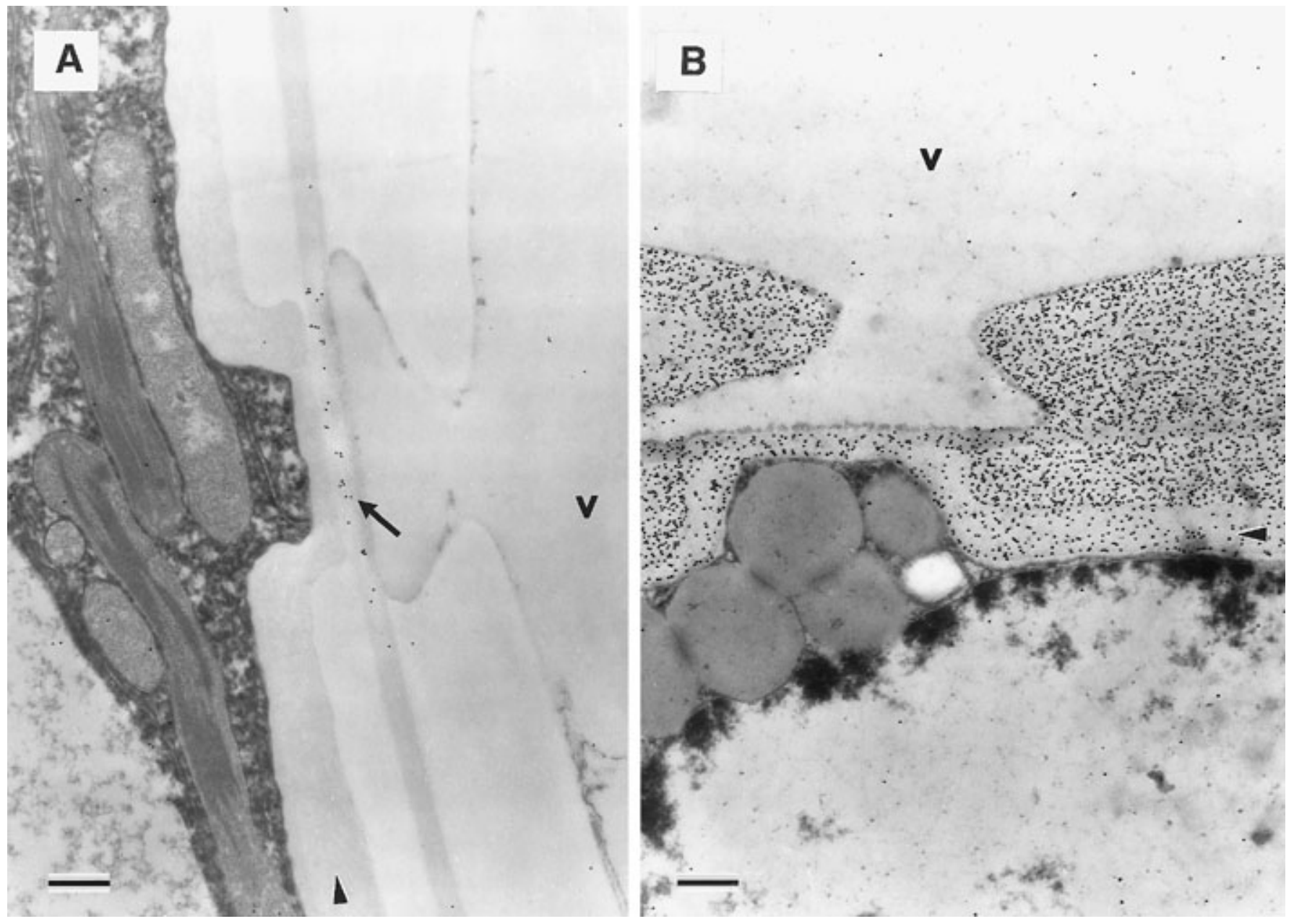

Fig. 1. Sections from samples collected from a nonwounded and a water-injected branch (12 days after injection) of Prunus pensylvanica. Bar $=0.3 \mu \mathrm{m}$. A, Labeling for pectin with JIM7 showing many gold particles over the pit membrane (arrow), whereas no significant labeling is discernible within the protective layer (arrowhead) and the vessel element $(\mathrm{V})$. B, Intense labeling with the exoglucanase-gold complex is seen over secondary walls of the vessel element $(\mathrm{V})$ and the parenchyma cell, as well as over its protective layer (arrowhead). The weak labeling observable in the vessel lumen and in the cell cytoplasm is comparable to background gold particles.
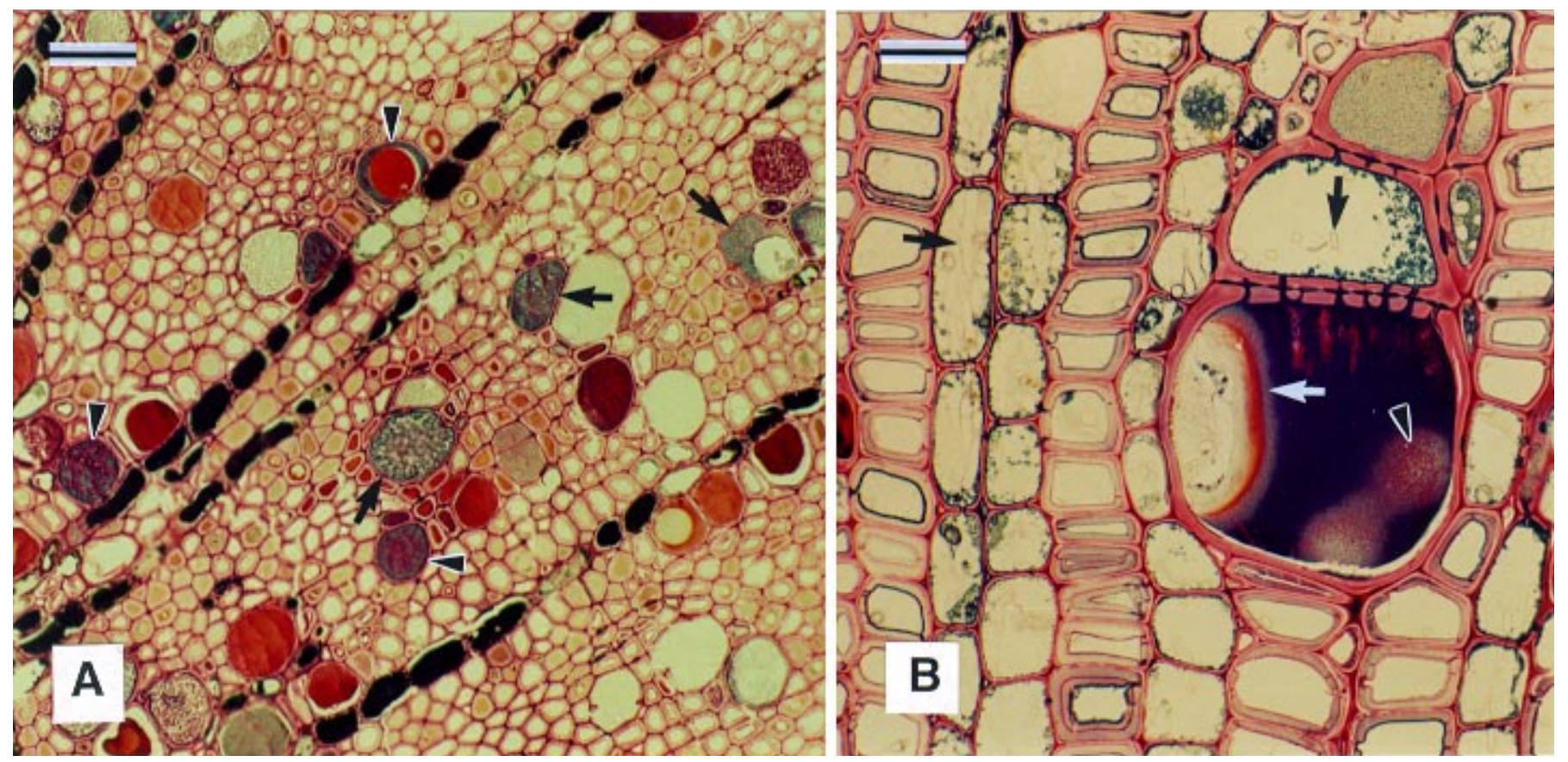

Fig. 2. Light microscope observations of sections stained with safranin and toluidine blue. A, Most of the gels formed in vessels of Prunus pensylvanica are stained red, some appear predominantly blue (arrows), and others disclose both colors (arrowheads) ( 28 days postinoculation). Bar $=30 \mu \mathrm{m} . \mathbf{B}$, A tylosis (white arrow) and a gel completely occlude this vessel element in Hevea brasiliensis. The gel is mainly stained blue, but some parts appear mostly red (arrowhead). Fungal cells with poorly stained cytoplasm can be seen everywhere in this section (black arrows). Bar $=25 \mu \mathrm{m}$. 


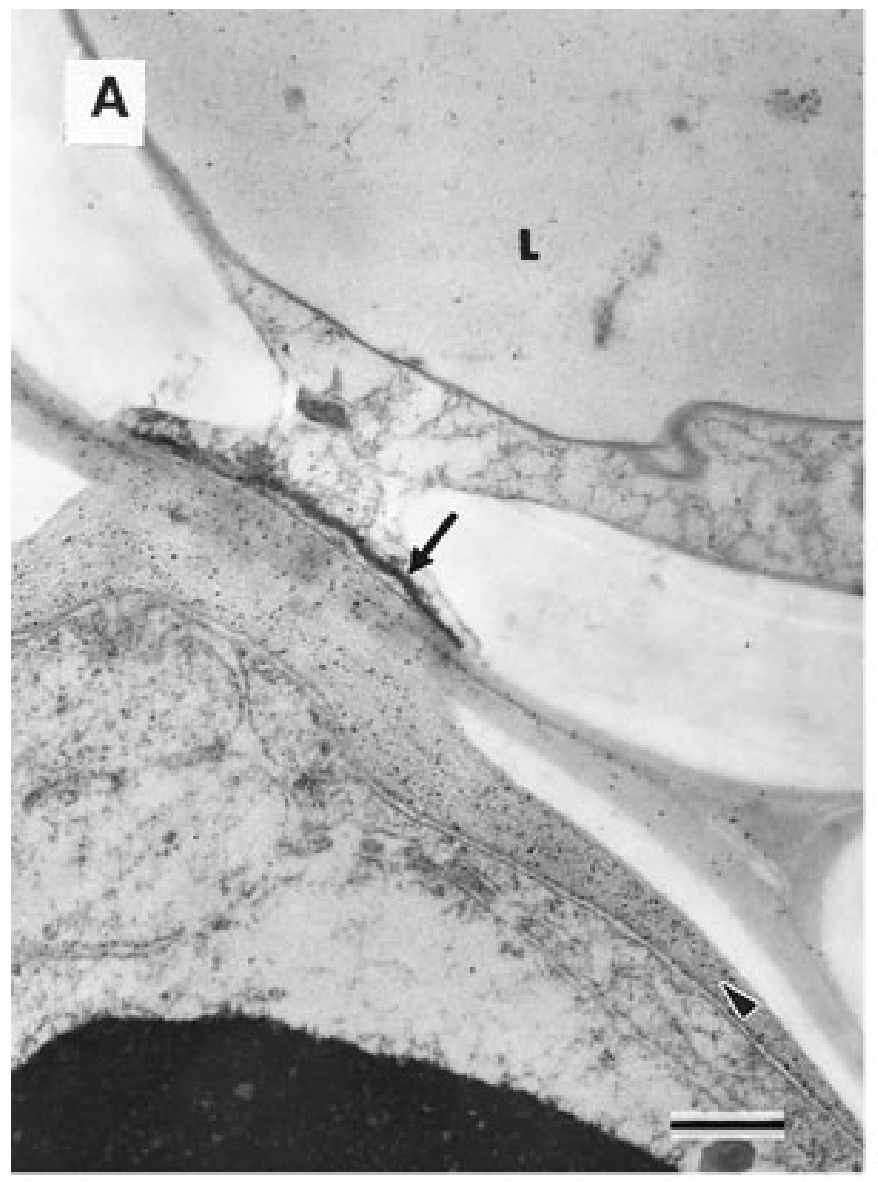

B
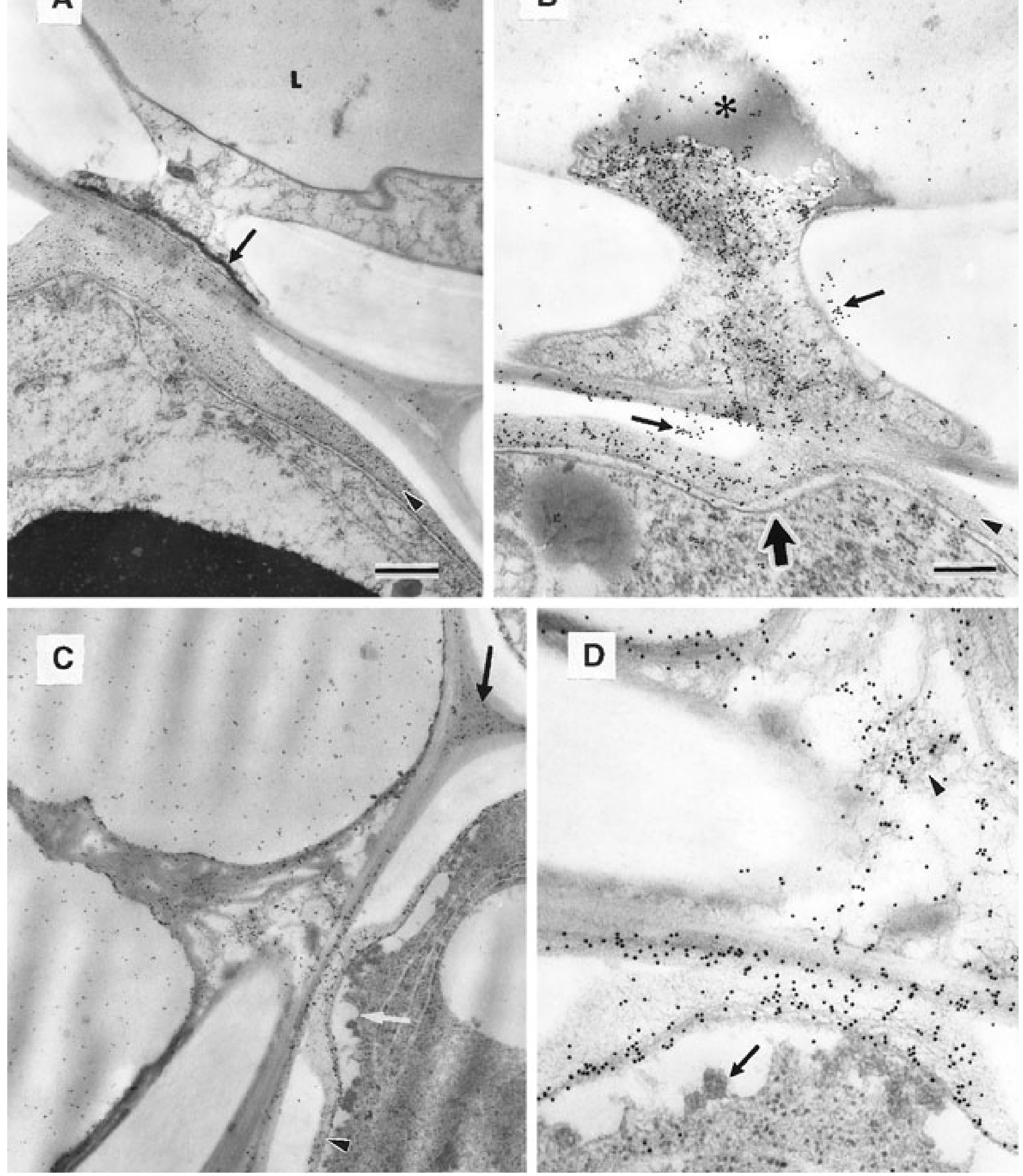

Fig. 3. Transmission electron microscope (TEM) observations of gel formation in Prunus pensylvanica stem segments collected at 2 to $3 \mathrm{~mm}$ from the inoculation point. Immunogold labeling with JIM5 (12 days postinoculation). A, Gold particles are intensely distributed over the protective layer (arrowhead) and the pit membrane; the latter is covered by an electron-opaque layer (arrow). Only scattered labeled fibrils are shown in the vessel lumen $(\mathrm{L})$ and the pit chamber. Bar $=0.5$ $\mu \mathrm{m}$. B, Labeled pectin fibrils are abundant in front of the pit membrane in this vessel element. The pectin is covered by weakly labeled material having an amorphous structure $(*)$. The plasmalemma appears slightly detached (large arrow) from the labeled protective layer (arrowhead). Higher than usual background labeling is noticeable over two small portions of secondary walls (small arrows). Bar $=0.3 \mu \mathrm{m}$. C, Intense labeling is shown in the vessel lumen, in the protective layer (arrowhead), and over the junction of xylem cells (black arrows) corresponding to the middle lamella. The area where the plasmalemma is retracted (white arrow) is shown at a higher magnification than in $\mathbf{D}$. Little or no labeling is visible over the secondary walls. Bar $=0.5 \mu \mathrm{m}$. D, Labeled pectin fibrils are observable in the protective layer and in the vessel lumen (arrowhead). Some unidentified material appears protruding (arrow) from the retracted plasma membrane. Bar $=0.2 \mu \mathrm{m}$. 

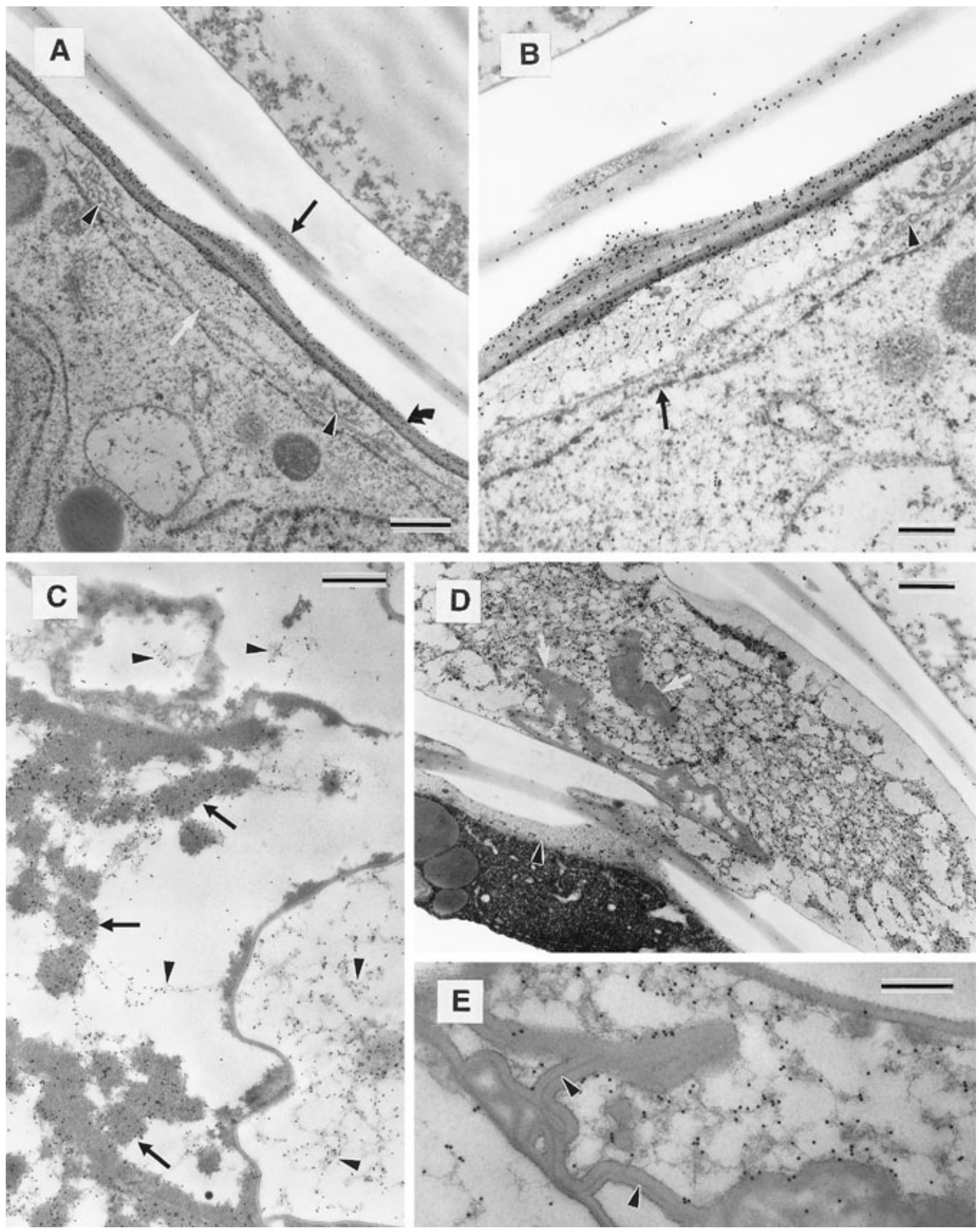

Fig. 4. Transmission electron microscope (TEM) observations of gel formation in Prunus pensylvanica stem segments collected at 2 to $3 \mathrm{~mm}$ from the inoculation point. Immunogold labeling with JIM5 (12 days postinoculation). A, Retraction of the plasmalemma (white arrow) opposite a half-bordered pit; only a small part of the pit chamber (black arrow) is shown by this section. The protective layer (curved arrow) is heavily labeled as is some fibrillar material present between this wall layer and the retracted membrane. Numerous unlabeled vesicles (arrowheads) are visible close to the labeled fibrillar material (higher magnification in $\mathbf{B}$ ) in the space left by the detached membrane. Bar $=0.5 \mu \mathrm{m}$. B, Some vesicles close to the labeled material might be produced by the extant plasmalemma (arrowhead), whereas an electron-opaque layer (arrow) might represent a new plasma membrane in formation. Bar $=0.3 \mu \mathrm{m}$. C, Plugging material in a vessel element composed of intensely labeled loosely aggregated fibrils (arrowheads) and more compact fibrillar masses (arrows) over which the number of gold particles appears slightly reduced. Bar $=0.5 \mu \mathrm{m}$. $\mathbf{D}$, The vessel element is almost completely occluded by labeled fibrillar material and by more compact amorphous masses nearly devoid of labeling (white arrows). The adjacent parenchyma cell has a weakly labeled protective layer (arrowhead) and its cytoplasm presents an abnormal appearance. Bar $=0.5 \mu \mathrm{m}$. E, Labeled fibrillar pectic material in a vessel element accompanied by unlabeled bands of material forming an electron-opaque demarcation (arrowheads) where they meet. Bar $=0.3 \mu \mathrm{m}$. 
rectly supported by other studies that demonstrated the porosity of the protective layer using traceable staining solutions $(4,56)$, leading to the proposal that this layer is primarily laid down to maintain some apoplastic transport around xylem parenchyma cells that are generally surrounded by quite impermeable lignified walls (4). In a previous study (38), tyloses were at times shown to secrete great amounts of pectic material in certain vessel areas that the tylosis primary wall could not clog completely such as the pit chambers, void spaces left between contiguous tyloses and the vessel wall, the vicinity of the rim of vessel perforation plates, and near certain parts of the vessel where the curving angle of the secondary wall is very pronounced. However, in light of the current observations, it now seems more appropriate to state that the material was secreted all around the tylosis primary wall before being pushed towards the previously mentioned areas when these tyloses completed their expansion. The release of pectic compounds from tylosis cell walls was also cytochemically revealed in cassava xylem vessels infected by xanthomonad bacteria (23). Another possible role of pectin might be to cement the tylosis wall to the other structures it encounters during tylosis development. Many authors have indicated that the appearance of the tylosis external wall layer was similar to a middle lamella $(10,21,32)$; the latter is known to be rich in pectic poly- saccharides and thus likely apt to provide good cohesion between adjoining cells (16).

At the species level in angiosperm trees, the rule is that only one type of plug is found in vessel elements (10). In the few species that may concurrently form tyloses and gels in the affected xylem area, the question of whether pectin originated directly from parenchyma cells or from tyloses might be occasionally difficult to resolve, as shown by a micrograph in elm (Fig. 7D).

Gel and tylosis formation has often been reported as being coincident with resistance to many plant diseases $(1,14)$. As most phytopathogens seem to be able to produce at least one type of pectic enzyme (27), and especially those that cause soft-rot diseases (55), and if vessel conditions are favorable for fungal growth, the pathogen might readily degrade the occluding pectinaceous substances and use them as an energy source. Many microscopic studies provide an indirect support of this point of view by showing that many pathogens can colonize host tissues by penetrating through middle lamellae $(23,58)$. However, these occlusions might improve plant resistance to diseases by acting as sites of accumulation of fungitoxic substances or by combining with compounds such as phenols, lignin, or suberin, as has frequently been suggested $(3,25,32-34,36,38-40)$. Our TEM observations of material from advanced stages of infection clearly revealed the heterogene-

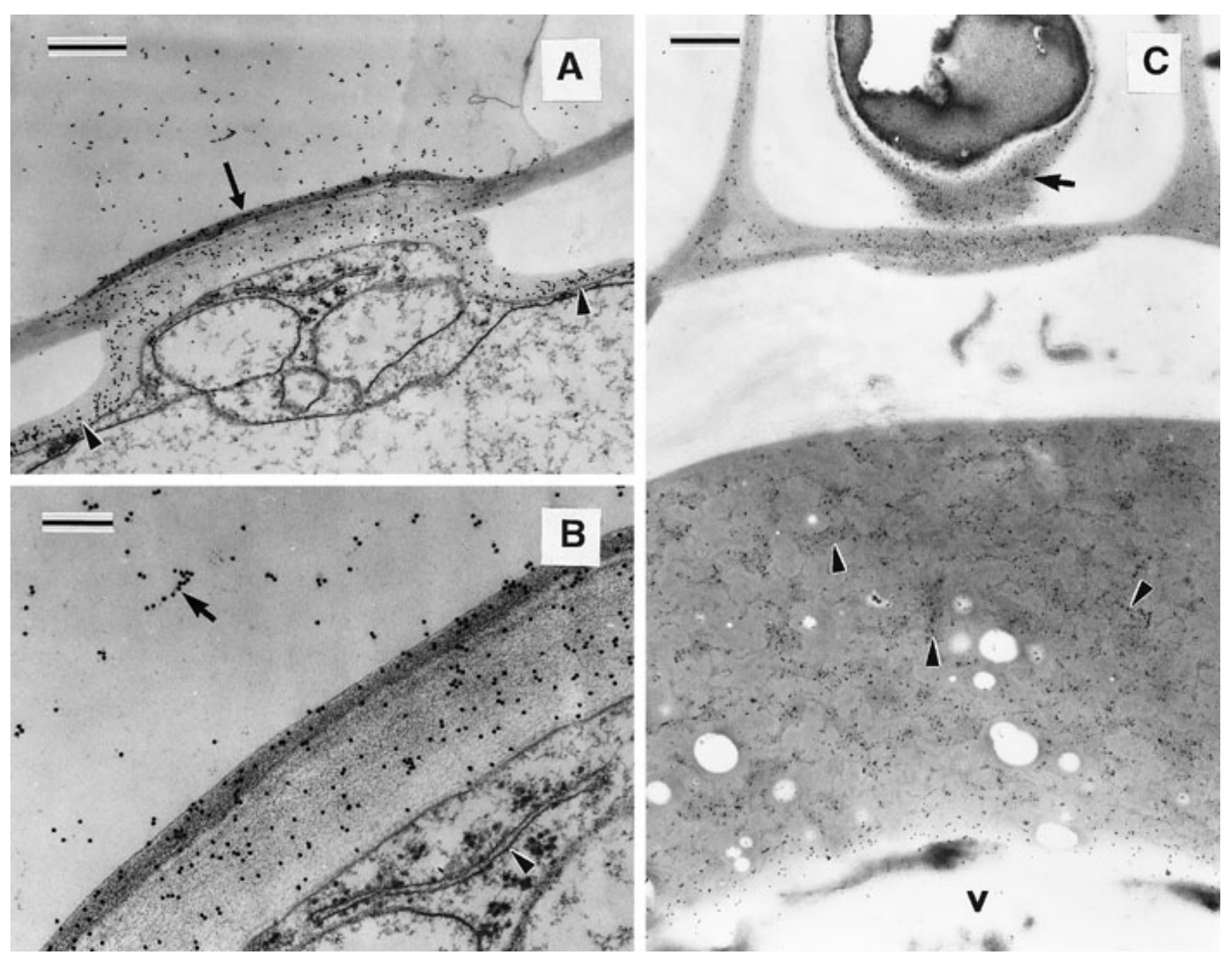

Fig. 5. Gel formation in Ulmus americana. Immunolabeling with A, JIM5 and C, JIM7. A, This stage seems to represent the beginning of the secretion process, as the labeling in the vessel element is only found in front of the pit membrane over pectin fibrils (higher magnification in $\mathbf{B}$ ). Gold particles are abundant over the protective layer (arrowheads), the pit membrane, and its electron-opaque covering layer (arrow) (natural infection). Bar $=0.4 \mu \mathrm{m}$. B, The fibrillar appearance of pectin is discernible beneath the gold particles (arrow). Rough endoplasmic reticulum (arrowhead). Bar $=0.2 \mu \mathrm{m}$. C, The lumen of this vessel element (V) is partly blocked by labeled fibrillar pectin (arrowheads) and more compact masses mostly devoid of labeling. The cytoplasm of the adjacent parenchyma cell appears greatly altered and its protective layer is strongly labeled (arrow) (49 days postinoculation). Bar $=0.5 \mu \mathrm{m}$. 

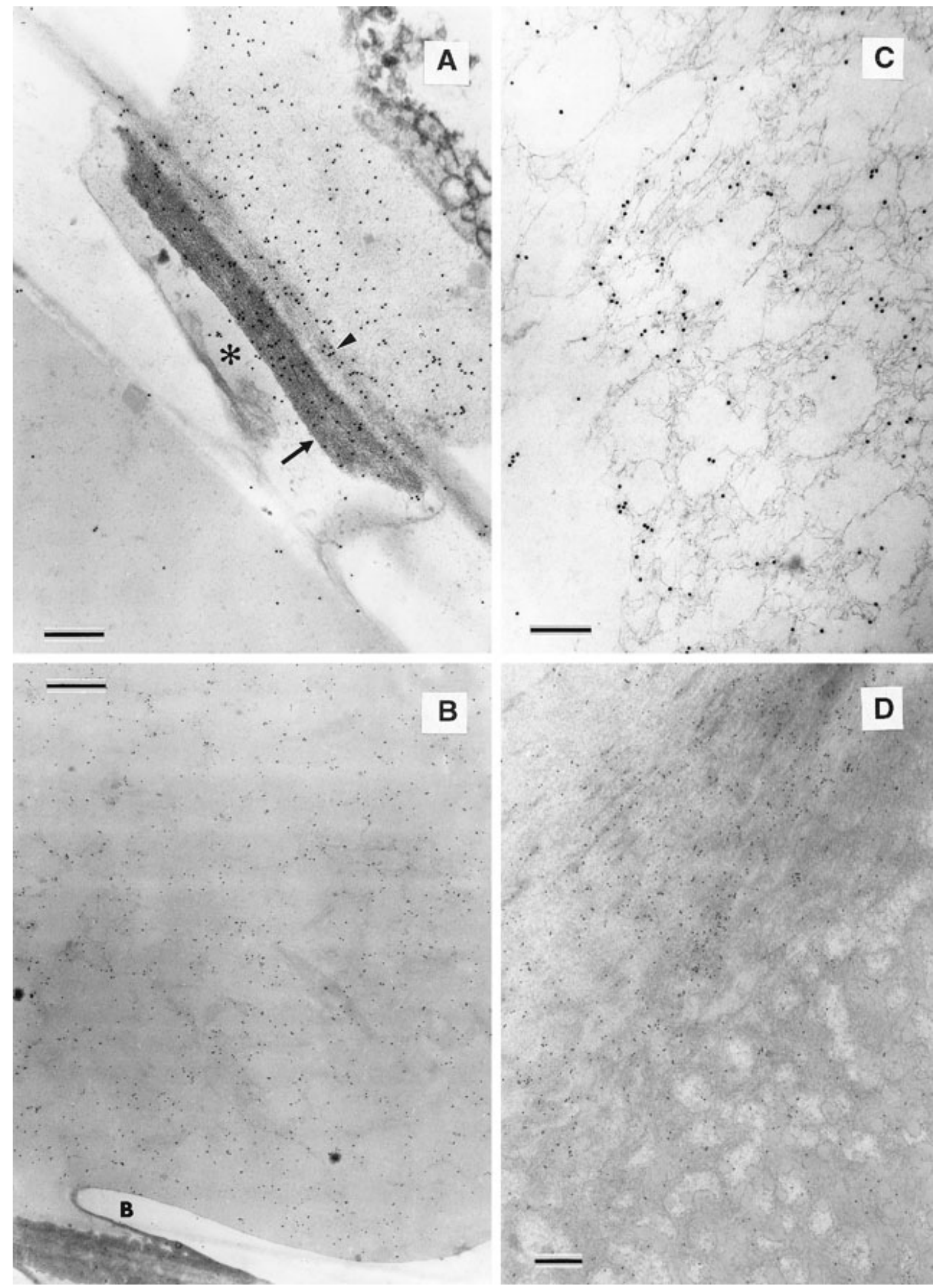

Fig. 6. Immunogold labeling with JIM5 over fibrillar pectin material involved in gel formation in A to C, Sorbus americana (10 days postinoculation) and $\mathbf{D}$, Hevea brasiliensis. A, The pit membrane (arrowhead), the electron-opaque cap (arrow) over it, and the protective layer are positively labeled for pectin as this cell appears to be beginning to react to the inoculation. Few gold particles occur in the pit chamber $(*)$ and in the lumen of the vessel element. Bar $=0.3 \mu \mathrm{m}$. B, This vessel element is completely occluded by material mostly composed of labeled pectic fibrils. Border of the pit (B). Bar $=0.5 \mu \mathrm{m}$. C, At a higher magnification in loosely aggregated material in vessel elements, the fibrillar structure of labeled pectin is clearly revealed. Bar $=0.2 \mu \mathrm{m}$. D, The gel occluding this vessel element in H. brasiliensis is labeled and appears fibrillar at the upper left, whereas the more compact matter at the lower right is only weakly labeled. Bar $=0.3 \mu \mathrm{m}$. 
ous nature of gels, for example, by showing the presence of more compact matter that did not label with the JIM antibodies. Similar unlabeled matter has also been observed within or close to the external wall layer of some tyloses $(23,38)$. One might be inclined to believe then that this amorphous material, which often occurs in close contact with microfibrils, might have been partially composed of pectin that became modified over time or had formed complexes with other unidentified masking compounds. However, in plants infected with vascular bacterial pathogens, it was demonstrated, using aniline blue (11) and polyclonal antibodies raised against $\beta$-1,3-glucans (23), that callose was part of similar amorphous material.

In light of these considerations and of the current results showing that wounding alone could also induce pectin secretion, embolism appears to be the primary trigger of the formation of vessel occlusions. Elm has been described as one of the most vulnerable
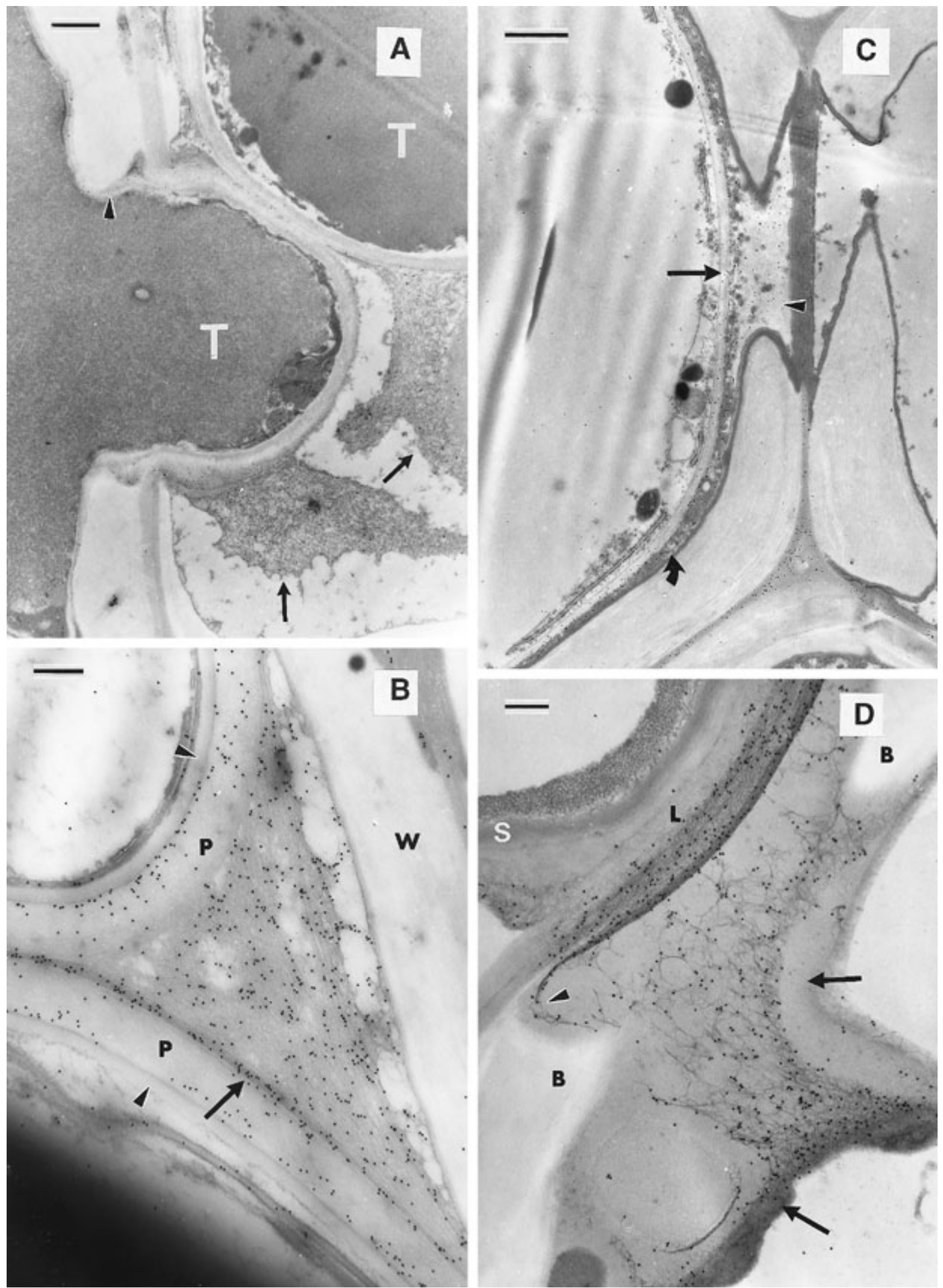
tree species to embolism (59). In agreement with this finding, our observations have shown that pectin secretion in elm was more intense in water-injected controls than in similar controls from the other tree species studied. Zimmermann and McDonough (59) also suggested that vessel occlusions do not contribute significantly to the interruption of sap transport, but rather are formed subsequent to vessel dysfunction following embolism both in woody and nonwoody plants. It has also been proposed that all the mechanisms, including vessel occlusions, originally proposed to limit the spread of microorganisms during compartmentalization of the xylem in trees (47), would be primarily induced as a response to embolism in order to prevent desiccation of adjacent healthy tissues (8). In so doing, diseased trees would concomitantly impede pathogen progression and the extent of embolism that always seems to accompany the development of microorganisms in the xylem $(8,59)$. Similar defense reactions to compartmentalize invaded xylem tissues have also been described in a diseased herbaceous plant species (3).

To achieve the complete occlusion of the conducting cells, it would be useful if pectin fibrils were able to swell if enough water were present therein. This swelling might also keep the water con- tent above a critical level, at least in adjacent cells and perhaps also farther away in the same vessel if it were sufficiently long. Following the use of JIM5 and JIM7 antibodies, pectin of the protective layer of xylem parenchyma cells in Prunus persica was shown to be the major component involved in preventing water loss from xylem parenchyma cells following exposure to freezing temperatures (57). In addition, Koran and Yang (22) pointed out that gums observed in vessels of Betula alleghaniensis and suspected to be composed of pectin could swell and shrink upon absorption or loss of water. In the current study, the early stage of pectin secretion was frequently observed in apparently somewhat functional vessels since they did not usually permit the local accumulation of microfibrils, for instance in front of the pit membrane. This suggests that pectin was dispersed along with the remaining sap movement. In that case, it is likely that pectin could be brought to aggregate and swell following impregnation with the water still remaining in these vessels.

To our knowledge, the occurrence of an electron-opaque layer or a "black cap" over half-bordered pit membranes (Figs. 3A, 5A, $6 \mathrm{~A}$, and 7D) has been described in only one other study (57). These authors showed that this cap labeled intensely with JIM5

Fig. 7. Immunogold labeling for pectin using the JIM5 antibody during development of tyloses in $\mathbf{A}$ and $\mathbf{B}$, Populus balsamifera 55 days postinoculation and $\mathbf{C}$, Ulmus americana 21 days postinoculation and $\mathbf{D}$, from natural infection. A, These tyloses (T) have produced material (arrows) that is positively but weakly labeled for pectin. The protective layer (arrowhead) is in continuity with the tylosis wall. Bar $=0.5 \mu \mathrm{m}$. B, Accumulation of pectin is shown between the positively labeled primary wall $(\mathrm{P})$ of these two tyloses and the vessel secondary wall (W). The external wall layer (arrow) of a tylosis is intensely labeled. Suberized wall layers (arrowheads). Bar $=0.3 \mu \mathrm{m}$. C, The labeling for pectin is positive over the tylosis primary wall (arrow) and over material (curved arrow) located between the tylosis wall and the vessel secondary wall. Note the positive labeling in the left portion (arrowhead) of the chamber of the bordered pit, whereas gold particles are very scarce in the right portion in a vessel that apparently was not occluded by a tylosis. Bar $=1 \mu \mathrm{m}$. D, The labeled fibrillar material might originate either from the two tyloses (arrows) or the paratracheal parenchyma cell. The latter may not be very active for secreting at this stage, as the protective layer (L) is only weakly labeled and as an impervious suberized layer (S) has been formed internally. The pit membrane and the electron-opaque layer over it are positively labeled, and the latter appears in continuity with the fibrillar material (arrowhead) in the chamber. The primary wall of the tylosis (arrow) at the top is visible, but the arrow at the bottom points only to the pectinaceous external wall layer of a tylosis as its wall was broken between this layer and the primary wall. Border of the half-bordered pit $(\mathrm{B})$. Bar $=0.3 \mu \mathrm{m}$.

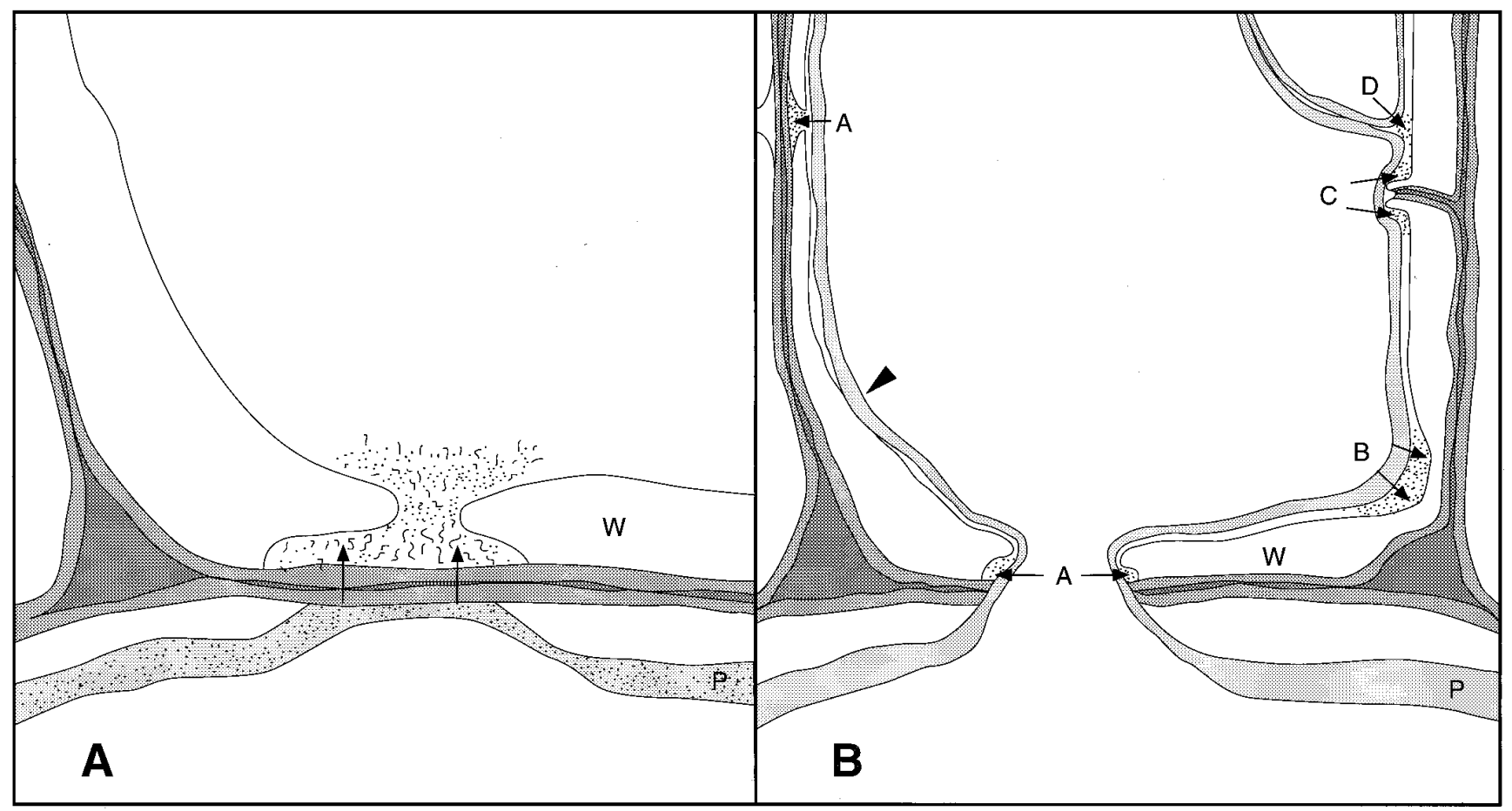

Fig. 8. Schematic representation of the production of pectin during gel and tylosis formation. $\mathrm{P}=$ protective layer and $\mathrm{W}=$ vessel secondary wall. $\mathbf{A}$, The pectin microfibrils, the basic component of gels, are transported via the protective layer before being secreted (arrows) into the adjacent vessel element. B, The tylosis primary wall, in continuation with the protective layer, allows the secretion of pectin that eventually may be observed to have accumulated in areas that the tylosis primary wall has difficulty reaching, such as the chamber of bordered or half-bordered pits (A); in vessel areas where the curving angle of the secondary wall is pronounced (B); near the rim of vessel perforation plates (C); and in areas between contiguous tyloses and the vessel secondary wall (D). A band of pectin (Fig. 7C) is usually present between the tylosis primary wall and the vessel secondary wall, except where the tylosis is in close contact with the vessel secondary wall (arrowhead). 
but not with JIM7, a result indicating that the pectin was mostly unesterified. They suggested that the black cap might be a pectin gel structure forming a greater barrier to water movement and ice propagation as a response to freezing temperatures. Our observations did not disclose if there was a clear-cut difference between the labeling obtained over this layer with JIM5 and JIM7. However, as this cap was only observed in samples taken from branches that obviously may have suffered embolism, it might be involved in limiting the loss of water from these parenchyma cells, which could give them enough time to respond to the injury. This type of cap was also observed in material from Quercus rubra collected during winter months (D. Rioux, unpublished data) where they might assume a function similar to that proposed by Wisniewski and Davis (57).

The more abundant labeling obtained with JIM5 than with JIM7 in all the specimens observed, even at the beginning of secretion, appeared to contradict somewhat the generally accepted theory that pectin is synthesized in a highly methylated form and that only thereafter, for instance when it becomes incorporated in cell walls, is it deesterified $(19,46,48)$. Knowing that JIM5 can recognize pectin with only up to $50 \%$ esterification (20), our results indicate that much of the pectin was produced in a mostly unesterified form and was secreted as such in vessel elements. This condition might be advantageous to the tree, as the unesterified pectin could form links with cations such as $\mathrm{Ca}^{2+}$ and thus improve the strength of the gels (19). This kind of linkage might also increase pectin resistance to most pectolytic enzymes (27). It should be noted that some studies seem in agreement with our findings, as they showed that pectin could be at least partially deesterified at the moment of its synthesis $(15,42)$.

In the literature, the term 'gum' $(1-3,10,12,17,18,22,24,49)$ was employed more often than 'gel' $(7,14,39,52)$ to describe the material secreted by parenchyma cells to occlude conducting elements although, obviously, both terms applied to the same occluding material. In the food industry, the substance essentially composed of pectin, which is not a liquid or a solid, is always called a gel (5). Likewise, review papers on plant cell walls often mention that the most noticeable physical property of pectic polysaccharides is their ability to form gels (13). On the other hand, gum canal in angiosperm trees is the term widely accepted as the equivalent of resin duct of conifers. In that case, the gum is different from the material causing vessel blockages, as it appears to contain numerous components mainly originating from the lysis of cells located near the gum canal lumen $(28,41,50)$. In the current investigation, strong evidence has been presented that pectin is the main component of gels (gums). In light of the above-mentioned considerations and in order to obviate confusion, we strongly suggest that the term 'gel' be adopted in future studies to describe the pectin occlusions formed in conducting elements that directly result from secretion of parenchyma cells.

\section{ACKNOWLEDGMENTS}

We thank P. Cheers (Laurentian Forestry Centre) for editing the manuscript and C. Moffet (Laurentian Forestry Centre) for his technical assistance during photographic work. We also thank three anonymous referees whose comments helped us to improve the quality of this paper.

\section{LITERATURE CITED}

1. Aist, J. R. 1983. Structural responses as resistance mechanisms. Pages 33-70 in: The Dynamics of Host Defence. J. A. Bailey and B. J. Deverall, eds. Academic Press, Sydney, Australia.

2. Baayen, R. P. 1988. Responses related to lignification and intravascular periderm formation in carnations resistant to Fusarium wilt. Can. J. Bot. 66:784-792.

3. Baayen, R. P., Ouellette, G. B., and Rioux, D. 1996. Compartmentalization of decay in carnations resistant to Fusarium oxysporum f. sp. dianthi. Phytopathology 86:1018-1031.

4. Barnett, J. R., Cooper, P., and Bonner, L. J. 1993. The protective layer as an extension of the apoplast. IAWA (Int. Assoc. Wood Anat.) J. 14:163-171.

5. BeMiller, J. N. 1986. An introduction to pectins: Structure and properties. Pages 2-12 in: Chemistry and Function of Pectins. Symposium Series No. 310. M. L. Fishman and J. J. Jen, eds. American Chemical Society, Washington, DC.

6. Benhamou, N., Chamberland, H., Ouellette, G. B., and Pauze, F. J. 1987. Ultrastructural localization of $\beta$ - $(1 \rightarrow 4)$-D-glucans in two pathogenic fungi and in their host tissues by means of an exoglucanase-gold complex. Can. J. Microbiol. 33:405-417.

7. Bishop, C. D., and Cooper, R. M. 1984. Ultrastructure of vascular colonization by fungal wilt pathogens. II. Invasion of resistant cultivars. Physiol. Plant Pathol. 24:277-289.

8. Boddy, L. 1992. Microenvironmental aspects of xylem defenses to wood decay fungi. Pages 96-132 in: Defense Mechanisms of Woody Plants Against Fungi. R. A. Blanchette and A. R. Biggs, eds. Springer-Verlag, Berlin.

9. Boher, B., Kpemoua, K., Nicole, M., Luisetti, J., and Geiger, J. P. 1995. Ultrastructure of interactions between cassava and Xanthomonas campestris pv. manihotis: Cytochemistry of cellulose and pectin degradation in a susceptible cultivar. Phytopathology 85:777-788.

10. Bonsen, K. J. M., and Kucera, L. J. 1990. Vessel occlusions in plants: Morphological, functional and evolutionary aspects. IAWA (Int. Assoc. Wood Anat.) Bull. 11:393-399.

11. Bretschneider, K. E., Gonella, M. P., and Robeson, D. J. 1989. A comparative light and electron microscopical study of compatible and incompatible interactions between Xanthomonas campestris pv. campestris and cabbage (Brassica oleracea). Physiol. Mol. Plant Pathol. 34:285-297.

12. Catesson, A. M., Czaninski, Y., Péresse, M., and Moreau, M. 1976. Sécrétions intravasculaires de substances «gommeuses» par les cellules associées aux vaisseaux en réaction à une attaque parasitaire. Soc. Bot. Fr., Coll. Sécrét. Végét. 123:93-107.

13. Darvill, A., McNeil, M., Albersheim, P., and Delmer, D. P. 1980. The primary cell walls of flowering plants. Pages 91-162 in: The Biochemistry of Plants. Vol. I. The Plant Cell. N. E. Tolbert, ed. Academic Press, New York.

14. Dimond, A. E. 1970. Biophysics and biochemistry of the vascular wilt syndrome. Annu. Rev. Phytopathol. 8:301-322.

15. Doong, R. L., Liljebjelke, K., Fralish, G., Kumar, A., and Mohnen, D. 1995. Cell-free synthesis of pectin. Identification and partial characterization of polygalacturonate 4 - $\alpha$-galacturonosyltransferase and its products from membrane preparations of tobacco cell-suspension cultures. Plant Physiol. 109:141-152.

16. Esau, K. 1977. Anatomy of Seed Plants. John Wiley \& Sons, New York.

17. Gagnon, C. 1967. Histochemical studies on the alteration of lignin and pectic substances in white elm infected by Ceratocystis ulmi. Can. J. Bot. 45:1619-1623.

18. Harling, R., and Taylor, G. S. 1985. A light microscope study of resistant and susceptible carnations infected with Fusarium oxysporum f.sp. dianthi. Can. J. Bot. 63:638-646.

19. Jarvis, M. C. 1984. Structure and properties of pectin gels in plant cell walls. Plant Cell Environ. 7:153-164.

20. Knox, J. P., Linstead, P. J., King, J., Cooper, C., and Roberts, K. 1990. Pectin esterification is spatially regulated both within cell walls and between developing tissues of root apices. Planta 181:512-521.

21. Koran, Z., and Côté, W. A. 1965. The ultrastructure of tyloses. Pages 319-333 in: Cellular Ultrastructure of Woody Plants. W. A. Côté, ed. Syracuse University Press, Syracuse, NY.

22. Koran, Z., and Yang, K.-C. 1972. Gum distribution in yellow birch. Wood Sci. 5:95-101.

23. Kpémoua, K., Boher, B., Nicole, M., Calatayud, P., and Geiger, J. P. 1996. Cytochemistry of defense responses in cassava infected by Xanthomonas campestris pv. manihotis. Can. J. Microbiol. 42:1131-1143.

24. Ludwig, R. A. 1952. Studies on the physiology of hadromycotic wilting in the tomato plant. Macdonald Coll. Tech. Bull. 20:1-40.

25. Mace, M. E. 1978. Contributions of tyloses and terpenoid aldehyde phytoalexins to Verticillium wilt resistance in cotton. Physiol. Plant Pathol. 12:1-11.

26. Meyer, R. W., and Côté, W. A. 1968. Formation of the protective layer and its role in tylosis development. Wood Sci. Technol. 2:84-94.

27. Mount, M. S. 1978. Tissue is disintegrated. Pages 279-297 in: Plant Disease-An Advanced Treatise. Vol. III. How Plants Suffer From Disease. J. G. Horsfall and E. B. Cowling, eds. Academic Press, New York.

28. Nair, M. N. B., Shah, J. J., and Subrahmanyam, S. V. 1983. Ultrastructure and histochemistry of traumatic gum ducts in the wood of Azadirachta indica A. Juss. IAWA (Int. Assoc. Wood Anat.) Bull. 4:103-112.

29. Nandris, D., Nicole, M., and Geiger, J. P. 1983. Infections artificielles de jeunes plants d'Hevea brasiliensis par Rigidoporus lignosus (K1.) Imaz. et Phellinus noxius (Corner) G. H. Cunn. Eur. J. For. Pathol. 13:65-76.

30. Nicole, M. R., and Benhamou, N. 1991. Cytochemical aspects of cellulose breakdown during the infection process of rubber tree roots by Rigidoporus lignosus. Phytopathology 81:1412-1420.

31. Nicole, M., Geiger, J. P., and Nandris, D. 1986. Root rot diseases of 
Hevea brasiliensis. II. Some host reactions. Eur. J. For. Pathol. 16:37-55.

32. Ouellette, G. B. 1980. Occurrence of tyloses and their ultrastructural differentiation from similarly configured structures in American elm infected by Ceratocystis ulmi. Can. J. Bot. 58:1056-1073.

33. Parameswaran, N., Knigge, H., and Liese, W. 1985. Electron microscopic demonstration of a suberized layer in the tylosis wall of beech and oak. IAWA (Int. Assoc. Wood Anat.) Bull. 6:269-271.

34. Pearce, R. B., and Holloway, P. J. 1984. Suberin in the sapwood of oak (Quercus robur L.): Its composition from a compartmentalization barrier and its occurrence in tyloses in undecayed wood. Physiol. Plant Pathol. 24:71-81.

35. Ramamoorthy, S., and Leppard, G. G. 1977. Fibrillar pectin and contact cation exchange at the root surface. J. Theor. Biol. 66:527-540.

36. Rioux, D. 1996. Compartmentalization in trees: New findings during the study of Dutch elm disease. Pages 211-225 in: Histology, Ultrastructure and Molecular Cytology of Plant-Microorganism Interactions. M. Nicole and V. Gianinazzi-Pearson, eds. Kluwer Academic Publishers, Dordrecht, the Netherlands.

37. Rioux, D., and Baayen, R. P. 1997. A suberized perimedullary reaction zone in Populus balsamifera novel for compartmentalization in trees. Trees 11:389-403.

38. Rioux, D., Chamberland, H., Simard, M., and Ouellette, G. B. 1995. Suberized tyloses in trees: An ultrastructural and cytochemical study. Planta 196:125-140.

39. Rioux, D., and Ouellette, G. B. 1989. Light microscope observations of histological changes induced by Ophiostoma ulmi in various nonhost trees and shrubs. Can. J. Bot. 67:2335-2351.

40. Rioux, D., and Ouellette, G. B. 1991. Barrier zone formation in host and nonhost trees inoculated with Ophiostoma ulmi. I. Anatomy and histochemistry. Can. J. Bot. 69:2055-2073.

41. Rioux, D., and Ouellette, G. B. 1991. Barrier zone formation in host and nonhost trees inoculated with Ophiostoma ulmi. II. Ultrastructure. Can. J. Bot. 69:2074-2083.

42. Schaumann, A., Bruyant-Vannier, M.-P., Goubet, F., and Morvan, C. 1993. Pectic metabolism in suspension-cultured cells of flax, Linum usitatissimum. Plant Cell Physiol. 34:891-897.

43. Schmitt, U., and Liese, W. 1990. Wound reaction of the parenchyma in Betula. IAWA (Int. Assoc. Wood Anat.) Bull. 11:413-420.

44. Schmitt, U., and Liese, W. 1992. Seasonal influences on early wound reactions in Betula and Tilia. Wood Sci. Technol. 26:405-412.

45. Schmitt, U., and Liese, W. 1993. Response of xylem parenchyma by suberization in some hardwoods after mechanical injury. Trees 8:23-30.

46. Sherrier, D. J., and VandenBosch, K. A. 1994. Secretion of cell wall polysaccharides in Vicia root hairs. Plant J. 5:185-195.
47. Shigo, A. L. 1984. Compartmentalization: A conceptual framework for understanding how trees grow and defend themselves. Annu. Rev. Phytopathol. 22:189-214.

48. Staehelin, L. A., and Moore, I. 1995. The plant golgi apparatus: Structure, functional organization and trafficking mechanisms. Annu. Rev. Plant Physiol. Plant Mol. Biol. 46:261-288.

49. Stuehling, B. A., and Nelson, P. E. 1981. Anatomy of a tolerant chrysanthemum cultivar infected with Fusarium oxysporum f. sp. chrysanthemi. Phytopathology 71:1162-1168.

50. Subrahmanyam, S. V., and Shah, J. J. 1988. The metabolic status of traumatic gum ducts in Moringa oleifera Lam. IAWA (Int. Assoc. Wood Anat.) Bull. 9:187-195.

51. Tenberge, K. B., Homann, V., Oeser, B., and Tudzynski, P. 1996. Structure and expression of two polygalacturonase genes of Claviceps purpurea oriented in tandem and cytological evidence for pectinolytic enzyme activity during infection of rye. Phytopathology 86:1084-1097.

52. VanderMolen, G. E., Beckman, C. H., and Rodehorst, E. 1977. Vascular gelation: A general response phenomenon following infection. Physiol. Plant Pathol. 11:95-100.

53. Vian, B., Reis, D., Gea, L., and Grimault, V. 1996. The plant cell wall, first barrier or interface for microorganisms: In situ approaches to understanding interactions. Pages 99-115 in: Histology, Ultrastructure and Molecular Cytology of Plant-Microorganism Interactions. M. Nicole and V. GianinazziPearson, eds. Kluwer Academic Publishers, Dordrecht, the Netherlands.

54. Waggoner, P. E., and Dimond, A. E. 1955. Production and role of extracellular pectic enzymes of Fusarium oxysporum f. lycopersici. Phytopathology 45:79-87.

55. Williams, P. H. 1979. How fungi induce disease. Pages 163-179 in: Plant Disease-An Advanced Treatise. Vol. IV. How Pathogens Induce Disease. J. G. Horsfall and E. B. Cowling, eds. Academic Press, New York.

56. Wisniewski, M., Ashworth, E. N., and Schaffer, K. 1987. The use of lanthanum to characterize cell wall permeability in relation to deep supercooling and extracellular freezing in woody plants. I. Intergenic comparisons between Prunus, Cornus, and Salix. Protoplasma 139:105-116.

57. Wisniewski, M., and Davis, G. 1995. Immunogold localization of pectins and glycoproteins in tissues of peach with reference to deep supercooling. Trees 9:253-260.

58. Ylimartimo, A., Laflamme, G., Simard, M., and Rioux, D. 1997. Ultrastructure and cytochemistry of early stages of colonization by Gremmeniella abietina in Pinus resinosa seedlings. Can. J. Bot. 75:1119-1132.

59. Zimmermann, M. H., and McDonough, J. 1978. Dysfunction in the flow of food. Pages 117-140 in: Plant Disease-An Advanced Treatise. Vol. III. How Plants Suffer From Disease. J. G. Horsfall and E. B. Cowling, eds. Academic Press, New York. 